\title{
Geriatric Therapeutic Care - A Story to Tell about my Grand-Parents
}

\section{S. StegemanN}

Capsugel a division of Pfizer, Rijksweg 11, 2880 Bornem, Belgium

E-mail: sven.stegemann@pfizer.com

Sci Pharm. 2010; 78: 554

doi:10.3797/scipharm.cespt.8.L14

The dramatic changes in the demographics will increase the number of elderly people from today's $10 \%$ to $20 \%$ of the population in 2050 , which is considered of one of the biggest challenge for our society. Geriatric therapeutic care is a multidisciplinary task that starts early on in the therapy of older adults and involves all stakeholders, including the patient, clinicians, physician, pharmacist, nurse, pharmaceutical industry and sciences and health care providers and policy makers [1]. When chronic diseases develop along with the increasing age and people start to take regularly medicines. With other diseases or symptoms occuring additional medications are given in the best intend of curing. Various physiological, biological, physical and social functions are changing with age too, leading to an increasingly heterogeneous patient group of the people 65 years and older. With $30-50 \%$ of all prescription drugs elderly patients represent the majority of drug users; however, their needs are poorly recognized in drug products development as well as their perception on medicines and their individual goals in drug prescription and therapy. Changes in the physiological and functional capacities, declining cognitive functions, impaired vision [2], increasing motoric limitations [3], an increasing difficulty of swallowing [4] and an increasing number of chronic diseases occurs with age. Within our drug product development programs the needs of special patient populations like elderly have to be taken into consideration. Age related changes need to be better understood and integrated into an overall therapeutic care plan that reflects the patient expectations and goals in the therapy as well as the patient life style to be executable.

The author would like to thank all members of the 'Geriatric Medicines Society' for the contributions to this paper.

[1] Stegemann S, Ecker F, Maio M, Kraahs P, Wohlfart R, Breitkreutz J, Zimmer A, Bar-Shalom D, Hettrich P, Broegmann B. Geriatric drug therapy: Neglecting the inevitable majority. Ageing Res Rev. 2010; in press. doi:10.1016/j.arr.2010.04.005

[2] Evans JR, Fletcher AE, Wormald RP, Ng ES, Stirling S, Smeeth L, Breeze E, Bulpitt CJ, Nunes M, Jones D, Tulloch A. Prevalence of visual impairment in people aged 75 years and older in Britain: results from the MRC trial of assessment and management of older people in the community. $\mathrm{Br} \mathrm{J}$ Ophthalmol. 2002; 86, 795-800. doi:10.1136/bjo.86.7.795

[3] Atkin PA, Finnegan TP, Ogle SJ, Shenfield GM. Functional ability of patients to manage medication packaging: A survey of geriatric inpatients. Age Ageing. 1994; 23: 113-116. doi:10.1093/ageing/23.2.113

[4] Sheth N, Diner WC. Swallowing problems in the elderly. Dysphagia. 1988; 2: 209-215. doi:10.1007/BF02414428 